\title{
CALCULATION OF INDIRECT ELECTRICITY CONSUMPTION IN PRODUCT MANUFACTURING
}

\author{
ADRIENN KONCZ \& ATTILA GLUDOVATZ \\ University of Sopron, Hungary \& Eotvos Lorand University, Hungary.
}

\begin{abstract}
Electricity consumption has been analysed since 2016 at a Hungarian furniture company. At the beginning of the research, a cyber-physical system was created which is capable of storing and analysing data on energy consumption by the production machines. The speciality of the system is that it can collect not only data on energy consumption by the machines but also the system can compare the energy consumption with production data. The data is received from sensors, which are installed into the building management system via the company's own computer network. In this building management system, calculations can also be performed. All the collected and calculated data are entered into the company's big database. The data is analysed with a business intelligence system, and the results are presented to the management and the other employees of the company. With this cyber-physical system all equipment are followed up in terms of energy management. The measured data can be analysed together by manufacturing machines and time; this way production efficiency can be represented by indicators. The goal of this study is not only to aggregate the energy consumption of machines that directly produce, but also to relate the energy consumption of indirectly aggregated production support equipment to production data. To achieve this goal, a completely new sensor environment had to be built to provide data from the supporting devices. One of the key supporting equipment is the extractors. These devices consume a huge part of total annual energy consumption of the factory $(\sim 30 \%)$. Their energy consumption costs are indirectly related to production, but through research and development, consumption can already be managed directly and aggregate to the creating of a product.
\end{abstract}

Keywords: Energy management system, Direct and indirect costs, Industry 4.0, Timber industry.

\section{INTRODUCTION}

In the past years, we worked on an Industry 4.0 solution, which is connected to the energy management of a timber industrial company [1]. Research is carried out at one of the biggest furniture manufacturing companies in the world. They have an affiliated firm in Hungary, and we cooperated with their experts while building the system. Our Industry 4.0 solution is a self-developed system that was built for measuring, collecting, and analysing the electricity consumption data. Moreover, processes and other systems were integrated by us. In this paper, we are focusing on a new feature of energy management. With this new extension, the indirect energy consumptions related to the exhaust fans of the factory can be converted to the direct values. The main goal was to make a connection between the exhaust fans' partial electricity consumptions and the manufacturing machines' electricity consumptions. The exhaust fans work as supporting devices for manufacturing machines, because when a given machine is in operation, it is indispensable that the connected exhaust fan must work.

This paper is organized as follows. Before demonstrating the operation of the system, we investigated the relevant scientific literature in Section 2. The focus is on two main subjects: the direct/indirect cost calculation and the importance of energy management and its system [2]. We briefly summarize our earlier results and introduce the new motivations which led to the implementation of a new subsystem structure which is related to the exhaust fans. The parts of the subsystem are presented in detail together with the scientific results. With the help of this system, the company's management can make more precise decisions. 


\section{LITERATURE REVIEW}

While studying the state-of-the-art literature, we sought information from three important areas of the related scientific field. The first topic is the direct and indirect costs, about which we give a general overview in Section 2.1. The second topic is the importance of energy management in industry, which is discussed in Section 2.2. At the end of both sections we highlight the uniqueness of our research. There are several research works and publications on the topics of timber industry, energy management, Internet-of-Things (IoT) and production, but none of them focuses on these areas considered together. Examining the publications on these topics, the following can be highlighted: (1) In the paper of Kallam et al. [3], the focus is on IoT, and its elements related to energy management, but the main goal here was to implement communication between devices. This technically sums up the advantages and disadvantages of IoT technology, however, we study the application and benefits of communication. (2) In the study of Hashmi et al. [4], an IoT-based energy management system was developed from various tools and software. The communication between the elements of the system and the monitoring of the energy consumption of the examined devices (e.g., light bulbs) were emphasized. Compared to this work, we deal more with IoT-based energy management for a specific manufacturing company. (3) In the research of Li and Kara [5], the architecture of an IoT-based wireless system is presented. It is true that our system is also IoT-based and consists mainly of their wireless elements (sensors), but in [5] the temperature test was the main test environment, no production related elements were included in the system. In our research, the test environment was a real production environment in real time. (4) The publication of Avancini et al. [6] describes a similar system to the one we have developed. It is an IoT-based system, using sensors to measure energy consumption, but it is not about a specific industrial environment, but about the operation of the process in general. The main difference here is that we can also measure the number of pieces of products, compressed air emissions and the amount of exhaust air, and compare this data with the energy consumption data of the specific machines.

\subsection{Direct and indirect cost calculation}

To start and maintain a business activity, resources are required, namely manpower, work tools and other necessary work equipment. A business uses these resources to produce products or to provide services. The monetary value of these resource inputs is called the cost. In general, it is necessary to monitor and follow up what resources are used to maintain the business. Thus, the type of costs provides a solution. The type of costs expresses what kind of resource utilization caused the generation of costs.

A large part of the costs can already be determined at the time of preparing the plan, namely, which production process or product or service can be accounted for. Costs can be direct and indirect according to their accounting. Direct costs are those for which it can be determined at the time of their occurrence which product or service they are related to, so the way and extent of accountability are clear. In the case of indirect costs, the way of accountability cannot be determined at the time of incurrence; that is why only the cost centre is known. There are two types of indirect costs, the operating cost, and the general expenses.

The costs can be examined also according to their relationships to the production process. In this case, the cost is divided to basic costs and additional costs for analysis and design purposes. The basic costs are the costs that are the direct inputs of a given production process and closely related to the technological processes. These basic costs are accounted as direct 
costs. The additional costs are inputs related to the production management and production service, which are accounted as general expenses. The costs can be examined and aggregated according to the change in manufacturing. This aggregation plays an important role in the preparation of different economic decisions.

In a manufacturing company, costs are also usually allocated to different dimensions. Dimensions are characteristics and properties that can be attached to different accounting items. For example, if we attach a manufacturing machine or other production support equipment (they are in the Enterprise Resource Planning (ERP) system database) to a given accounting item, later we can analyse and sort these items along this dimension [7]. Thanks to this method, it can be known which manufacturing machine produces the most production pieces $\left(\right.$ or $\mathrm{m}^{2}$ ) or which manufacturing machine or other production support equipment consume the most energy at the given period. This way the machines and equipment can be compared in terms of energy consumption or productivity. A dimension can be for example a cost centre, whose values can be administrative, manufacturing and sales values. Another dimension can be totally different dimension values. To determine a dimension and its values there is no general rule, but it is always determined by the management of the company.

It is important to know the direct and indirect costs because manufacturing companies can integrate the indirect cost with only some fixed ratio or estimation. We would like to create a more precise solution to determine the indirect energy consumption costs.

\subsection{Energy management}

In addition to the financial and accounting side, it is also necessary to examine and manage energy management at a manufacturing company, since most costs are generated from energy consumption [8]. Energy cost is an important item and an ever-increasing burden for any business. Energy costs are influenced by factors beyond the control of companies; that is why without the application of an energy management system the losses go unnoticed, the unnecessary expenses have a negative impact on the profit, the economy, and the competitiveness. The importance of energy management is manifested in the following factors.

1. Exploration of savings reserves. The system focuses on bottlenecks by exploring consumption characteristics, cross-effects, low efficiency consumers and consumption points. This often triggers modernization with an attractive payback period and the ongoing projects lead to a further steady reduction in energy costs.

2. Increasing productivity. There is a strong correlation between energy efficiency and business profits. By exploring and quantifying this relationship, productivity can be enhanced. Energy efficiency often increases the will to use other resources within the business.

3. Decreasing emissions of harmful substances.

4. Decreasing maintenance costs and improving reliability. The system is able to signal problems before they occur, but it also benefits the life of the equipment by reducing and optimizing the load and reducing repair costs and downtime.

5. Higher level of middle and senior management control. Energy management provides insight into the internal processes of a company and its interrelations, which positively affects the development of a corporate energy strategy and the entire business.

6. Greater employee engagement. Businesses that continuously monitor their processes have a much more motivated and committed workforce, which positively impacts all other activities. 
One of the main goals of energy management is that the employees of the company can better know and understand the usage of the energy resources and the elements of efficiency improvement in the system, and through them they understand corporate processes and technologies. It is important in the life of the company to have a strong middle and senior management commitment and a clear strategy in addition to energy management. It is also important to set energy targets, which are transformed into a series of specific, measurable, and time-limited steps determined by an appropriate business and strategic plan. It is necessary to develop an appropriate tracking, measurement, and evaluation system to increase and monitor performance in relation to the energy targets. Effective external and internal communication about energy goals and strategies is essential for the company. Those companies, which can achieve a significant cost reduction and much lower energy consumption, they can be faced with mutually beneficial components in relation to financial, environmental, and positive operation effects. This will make energy management one of the top priorities of the business in the near future. Strengthening energy awareness within a company is ultimately playing an increasingly important role in the success of the business itself.

From the viewpoint of the energy management, our research is also an important step towards the company's compliance with the ISO 50001 energy management system certification. With this current research, we can determine useful or useless operations of not only the machines (directly connected to manufacturing), but also their supporting devices (indirectly connected to manufacturing). The company can reduce the detected useless operation and the loss in a targeted way for a given machine, at a given period, with a given group of employees.

\section{OUR ENERGY MANAGEMENT SYSTEM}

In this section, we introduce our energy management system, detailing the architecture and data flow of the core system.

\subsection{Core system architecture and data flow}

In the past years, a hardware and software framework was implemented and installed at the company [9]. Figure 1 shows the framework's structure and the data flowing processes. There are more than 100 devices and machines with installed sensors at the company. These sensors send the measured data to the building "Supervisory Control and Data Acquisition" (SCADA) system and the ERP system via network gateway. After that, the consumption and manufacturing data are joined with a Business Intelligence (BI) tool and its technique. BI tool represents the trends and the close connections between the datasets.

The main research directions were the following. At the beginning we analysed the machines' electricity consumption data and the produced quantities (pieces or $\mathrm{m}^{2}$ of timber boards). After that, possible defects of devices were estimated with trend analysis through the measured datasets. In the last year, we started to collect other resources' data, for example water consumption or the air quantity produced by the compressors [9].

\subsubsection{Manufacturing machines, supporting devices and their sensors}

The energy meters (sensors) with Modbus/TCP (Transmission Control Protocol) interface are particularly suitable for central data collection in industrial systems. A picture of such a device can be seen in Figure 2. The measuring devices record key electrical parameters such 


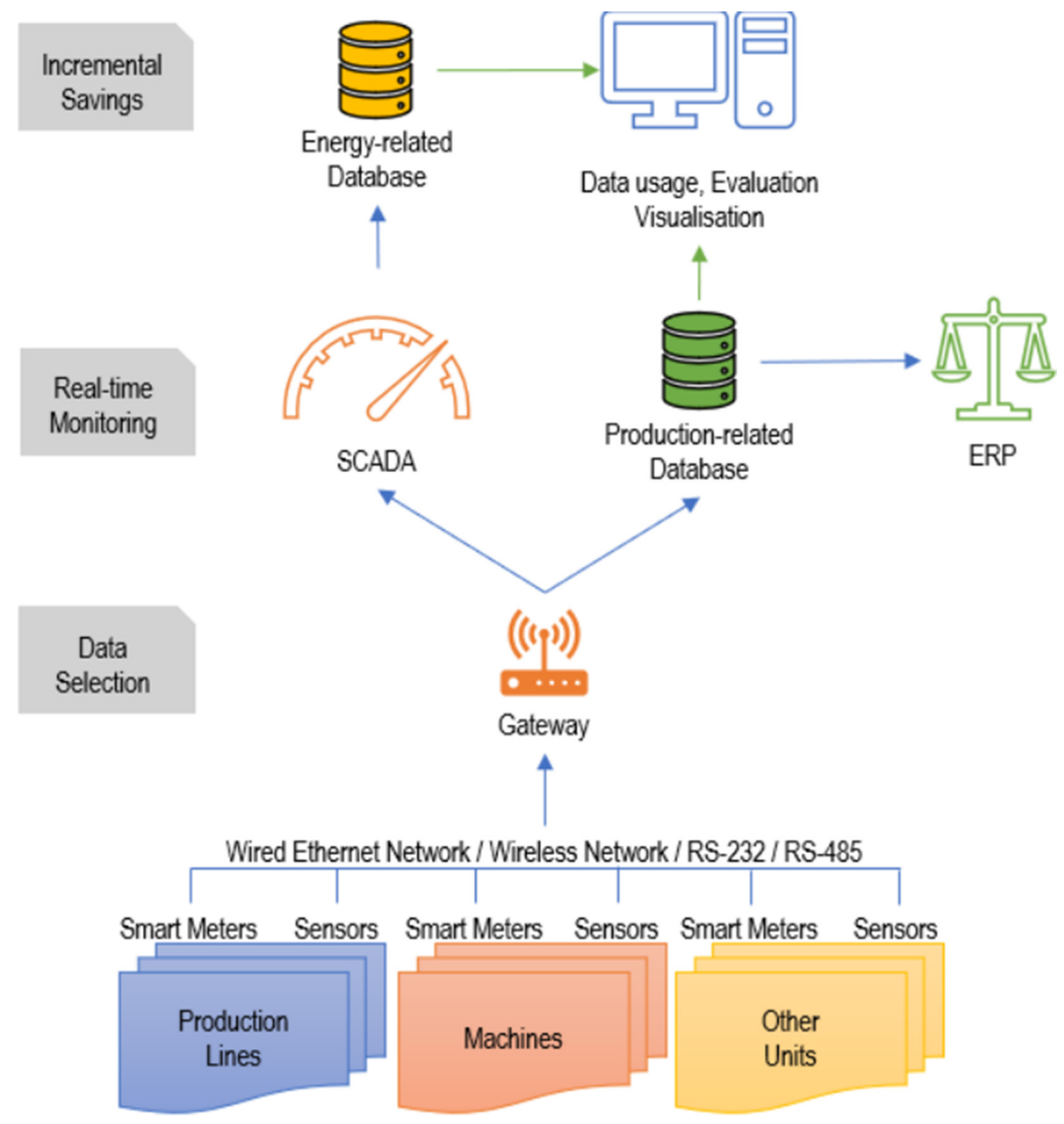

Figure 1: System architecture and data flow.

as currents, voltages, power factors, powers, and energy values in all four quadrants. The raw data from sensors run into the building supervisory system.

\subsubsection{SCADA system}

The SCADA system helps to monitor the system and save energy consumption data. In this higher-level control system, all trends can be seen in the measured data on charts in real time and can execute the remote control of the status of devices (machines) in the factory. The SCADA system can represent the collected datasets to the managers [10]. An actual value-set of the sensors are shown in Figure 3.

The data analysis process is not implemented in the SCADA system component, so we must save the data into an external Database Management System (DBMS) into our own structure. The SCADA system has its own programming language, with which the incremental saving routine was implemented. These data savings are the incremental backups, which means that only the new data will be loaded from SCADA to DBMS. For this purpose, a 


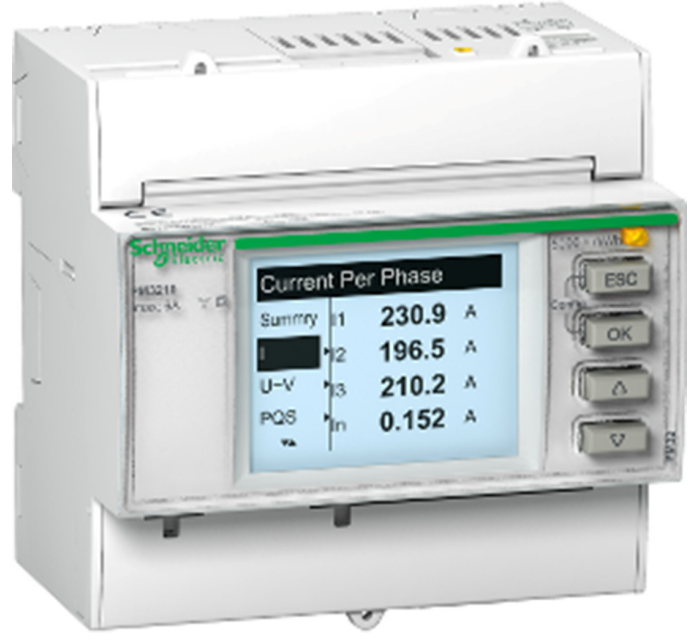

Figure 2: Power meter sensor.

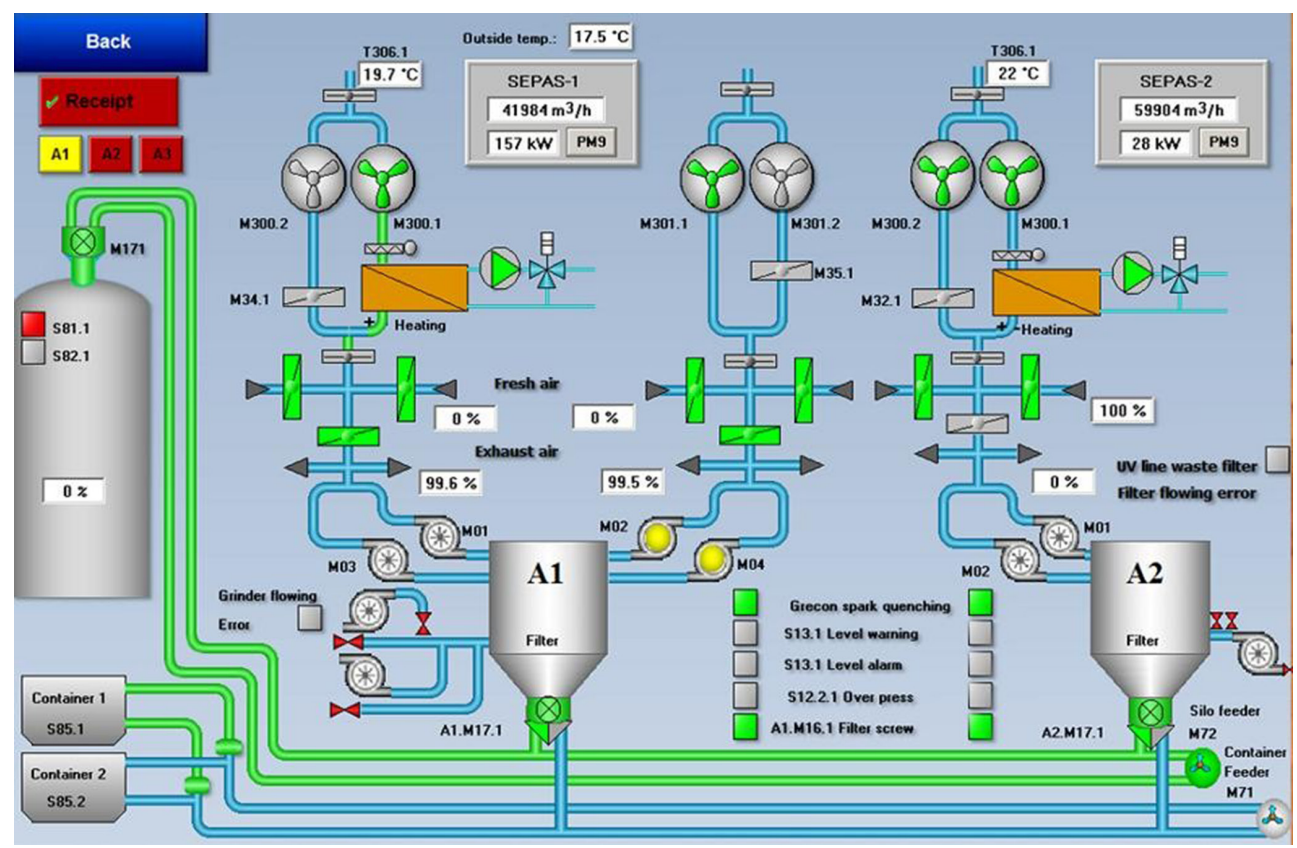

Figure 3: SCADA software screenshot about exhaust equipment system.

schedule was created for the repeating task which saves the data into the DBMS. This routine runs every 10-minutes which is enough. Even the biggest electricity consumers (a surface-handler machine and an exhaust fan) use together $100 \mathrm{kWh}$ (Kilowatt-hour) in every 10 minutes, so, the checking of electricity meters in every second or minute is not necessary for monitoring the electricity consumption in the factory. 
Regarding the numbers of the factory: there are one main electricity meter (certified by the official Hungarian Electricity Ltd.), 2 plants of the factory, 6 exhaust fans with 105 shutters, 9 compressors, 29 manufacturing machines and some other less important devices.

\subsubsection{Database structure for storing energy consumption data}

In the database, we created the base tables and populated them with data: for types of devices and the devices table. We prepared the tables for storing the measured data by device type: electricity consumption values by manufacturing machines, exhaust fans and compressors, produced/exhaust cubic meter of air by compressors/exhaust fans, and storing water consumption $\left(\mathrm{m}^{3}\right)$ values [11].

The sensors do not store their consumption values, no hourly, daily or weekly data is available either, therefore we need to make a calculation for getting the precious numbers from the sensors' meters. For storing new data, a procedure is configured in the database because of the calculation. This procedure contains the following sub-routines:

1. Validation of the new sensor data.

2. Conditional inserting statements:

a. if the new value is valid (not negative or too high according to the latest value), then calculate new field data,

b. if the new value is not valid, then "insert" nothing into the field data.

In the routine's new data calculation, the DBMS calculates the difference between the new sensor meter value and the old value (from the latest 10 minutes), and it will be the new data, which shows us how many kWh of electricity the device consumed within the last 10 minutes of an equipment (machines, extractors, compressors etc.).

\subsubsection{Enterprise Resource Planning system for manufacturing data}

The Enterprise Resource Planning (ERP) system is a unified information system, which accomplishes all information processing that occurs within a given company, and it supports company-wide integration [12]. An ERP system stands for both an application and for a concept. If somebody construes it as a concept, then they are talking about a company-wide design and management concept. According to this the ERP system maintains a connection between each business process, and between the company and the corporate environment. If somebody looks at it as an application, then with an ERP system they actually mean a software that supports the operation of enterprises and organizations. The ERP system is an IT solution that processes an organization's data and information and implements a unified, integrated IT management of the processes.

In ERP systems, organizational processes are monitored, resources available to the company and the organization's data are managed. ERP systems are integrated systems and operate in real or near real time. ERP systems use a common database structure and have a consistent appearance and operational logic in each module. The main components of ERP systems are the decision-making users, external and internal information, and external and internal hardware and software elements. The main functions of ERP systems are the standardization and automation of processes, collecting data generated during operations, transforming the data into usable information, and making the information available [13].

The ERP system is also essential software to our research because the production data of the company's production machines are recorded there. We can track how much time and how many pieces or $\mathrm{m}^{2}$ of each product were produced by each production machine. The data 
comes in aggregate from machines into the system. Each machine has a unique machine ID that allows us to identify them in the ERP system. We can divide the time measurements into arbitrary periods; thus, we can track the production numbers not only on a daily basis, but even with finer granularity, hourly or 10-minute data are also available This allows us to continuously monitor what products and how many pieces or $\mathrm{m}^{2}$ are produced by each manufacturing machine in every 10 minutes. The comparison can be checked at any time, so it can be also viewed aggregating into weeks, days, and 10 minutes. This way we can generate reports for the progress of our research and for the management that show how many pieces or $\mathrm{m}^{2}$ of products a given production machine produces in a given time period (days, hours or 10 minutes) and how much energy consumption this process involves in this given period. With this knowledge, the company's employees and management will be aware of the data already mentioned. If somebody detects negative results somewhere, for example too much energy consumption and low production, they can optimize the operations.

\subsubsection{Business Intelligence software for reporting}

Business Intelligence (BI) is a set of methods and concepts that improve the decision-making process with the help of so-called fact-based systems, for example Management Information System (MIS), Decision Support System (DSS), Data Mining (DM) [14]. In general, BI systems are implemented by companies to improve the availability of their existing data, that is, to make it easier, faster, and more widely available to access their data. BI provides solutions to the following problems: making reports and dashboards, development of indicators (Key Performance Indicators (KPI), Balanced Scorecards (BS)), business and statistical analysis, planning, forecasting, business modelling, consolidation, aggregation, time series analysis, customer segmentation, fraud detection, credit rating, cross-selling analysis, geographical analysis of data, data visualization, graphs, displays, and data, text and sound mining. It can be used to analyse sales, to analyse demand, to test price elasticity, or anything else that requires data, sounds, images, or text analysing.

From an IT perspective, BI is a whole range of technologies and software for IT. To build a BI system, more software is necessary. Typically, a database manager is needed where IT specialists will store the required data for the analysis, a data loader is required with which people can upload a BI system, and a display interface is also needed through which people can query the BI system data and modify its models. Accordingly, we distinguish between reporting technologies, analytical technologies, monitoring technologies and forecasting technologies. Reporting technologies provide an answer to what has happened. These include query, report making and search technologies. Analytical technologies answer the question of why. These include OLAP and data visualization technologies. Monitoring technologies answer the "What's happening now?" question. These include performance management tools, dashboards, and scorecards. Forecasting technologies answer the "What could happen?" question. Forecasting and data mining technologies belong to this category. The listed business intelligence technologies are becoming more complex and can have an increasing impact on the life, performance, and profit of the company [15].

With the help of BI, we were able to connect the production data (quantity numbers, product types, and production times) storing in the ERP system with the energy consumption data. At the company, the BI system stores the energy consumption data of all production machines and other production support equipment (extractors, compressors, fans). Creating various analyses from the existing data and generating reports from them supports the presentation to the management of the company. These reports clearly show the useful and useless energy 
consumption, the related production numbers and, of course, the periods. We can also track the energy consumption data of each manufacturing machine and equipment in the BI system. Each manufacturing machine and equipment are provided with a unique identifier (of course, in the ERP system, the same identifier is also displayed for the same given production machine), so we can filter the energy consumption divided by machines. The data is very easy to interpret in the BI system. We can examine the filters not only aggregated into machines, but also here we can set the desired periods (year, months, weeks, days, hours, 10 minutes) and filter by manufacturing equipment, by shifts, by date, by machine type and by any other arbitrary parameter. For example, the system can show how much energy an extraction device consumed every 10 minutes during a given shift, or how much energy a randomly selected production machine consumed on a given day, how many products were manufactured at intervals of up to 10 minutes. With our analyses, we have already been able to provide useful information to the management and help them in the decision making process, because the given information became visible to them as well, so they could intervene operatively in the processes where necessary, and it is also a great advantage for them in cost planning [16].

\subsection{New ideas, plans, motivations with the system}

During our literature research, we did not find any timber or furniture industry case studies; because of this we decided to focus not only on the electricity consumptions by the manufacturing machines or exhaust fans, but also on aggregating them with the manufacturing quantities. Thus, the company's management can get useful "energy performance indicators" about the factory's operation. Our framework is a self-developed system with the components of the company's hardware and software solutions. This was an important requirement of the company's management.

Figure 4 shows that the total electricity consumption is circa 12 million kWh in 2020 at the company. The exhaust ventilation system's parts consumed more than 3 million $\mathrm{kWh}$. But unfortunately, we could not connect these exhaust fans' measured data to the manufacturing performance. We wanted to make a connection between these parameters, thus the company gets not only indirect costs, but the direct costs of exhaust devices, too. Besides, we also wanted to know the quantities of useful and useless electricity consumption of exhaust ventilation system devices. Useful electricity consumption means that the machines created products; the useless electricity consumption means that the machines did not produce any products. For the purpose of converting indirect costs into direct costs, several changes and extensions were required in our cyber-physical framework.

\subsection{Extended system}

Based on the previously described motivations, the cyber-physical system environment had to be extended. New sensors were needed to monitor the exhausts' shutters statuses which indicate that a shutter is open or closed in every minute. Additional input data of the extended system are the following:

1. Electricity consumption of exhaust devices every 10 minutes.

2. Capacity of exhausted air quantity of all shutters (for example: one exhaust device has three shutters, and if a shutter is open, it can exhaust $4,000 \mathrm{~m}^{3}$ / hour).

3. Related manufacturing machines and their electricity consumption every 10 minutes. 


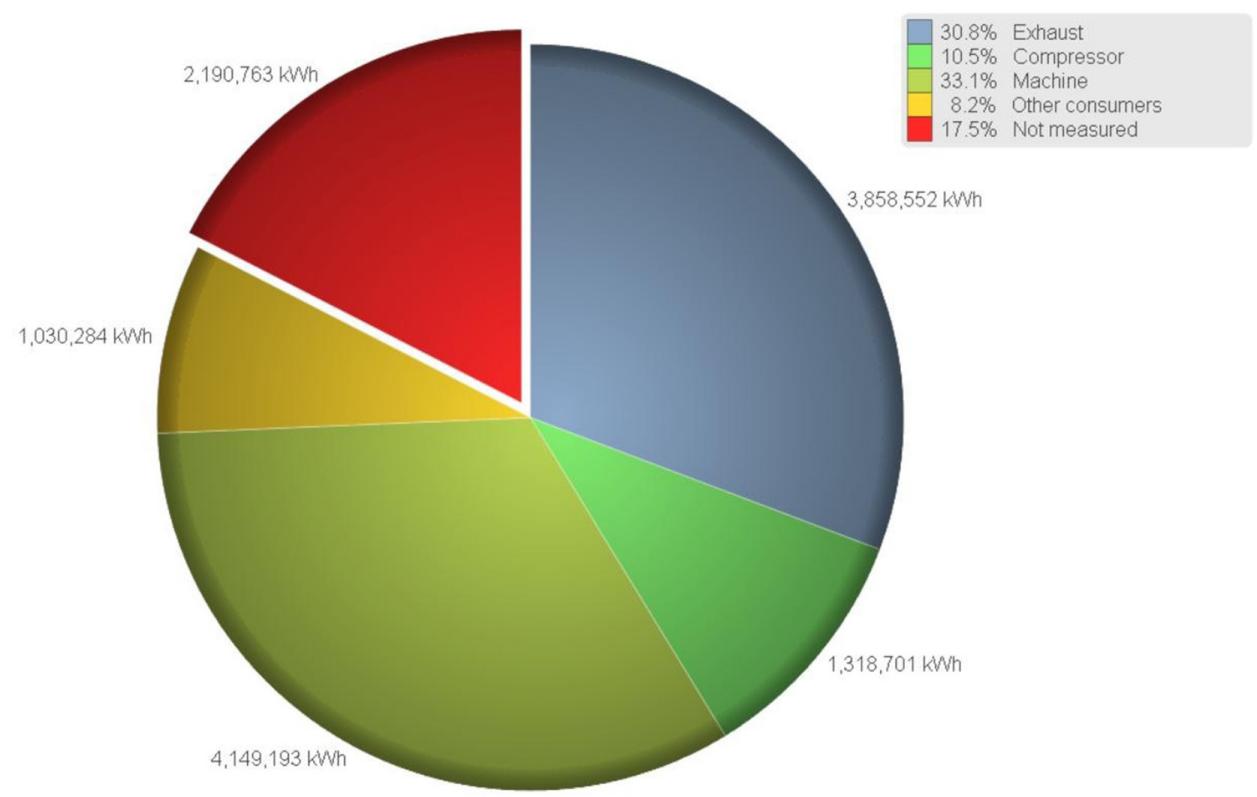

Total annual consumption of the factory: $12,547,493 \mathrm{kWh}$

Figure 4: Electricity consumption in 2020.
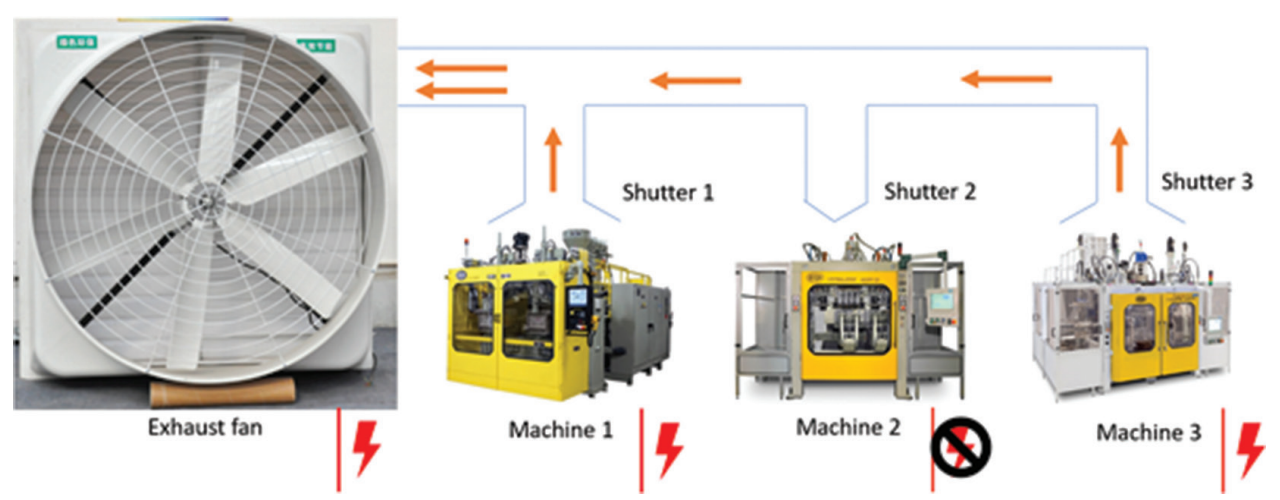

Figure 5: Main part of the extended system.

After every 10 minutes, our algorithm added proportionate (useful and useless values) consumption of exhaust fan to the related machine's energy consumption. Thus, we can get direct consumption data from indirect ones.

Figure 5 shows an exhaust fan device, which consumes electricity when it is working and exhausts air from three machines, when their shutters are open. In the example shown in Figure 5, the first and the third shutter are open, the second shutter is closed. If a shutter is open, then a partial electricity consumption of exhaust fan will be added to the related machine's electricity consumption data. 


\subsection{Converting from indirect to direct electricity consumption}

Our extended system was able to manage the new calculations to give us direct values from indirect exhausts' electricity consumptions.

\subsubsection{Formula for partial electricity consumption}

As we mentioned earlier, we would like to know the partial electricity consumption of exhaust fans to every shutter (and machine). We introduced a formula that gives the partial electricity consumption to shutter in each period (10-minute):

$$
E_{S_{i}}=\left\{\begin{array}{c}
\frac{E_{E X_{j}} * t_{i} * C_{i}}{\sum_{k=1}^{l} t_{k} * C_{k}} \rightarrow \text { if } \exists k: t_{k}>0 \\
0 \rightarrow \text { otherwise }
\end{array}\right.
$$

where:

- $j$ : identification of the related exhaust fan,

- $i$ : identification of the related shutter,

- $k$ : index variable,

- $l$ : the number of shutters of $j^{\text {th }}$ exhaust fan, and $1 \leq i \leq l$,

- $E_{s t}$ : the partial electricity consumption of the $i$ shutter of $j$ exhaust fan $(\mathrm{kWh})$,

- $E_{E X}$ : the total electricity consumption of the $j$ exhaust fan $(\mathrm{kWh})$,

- $t_{i}$ : the number of minutes (maximum 10), when the $i$ shutter was open,

- $C_{i}$ : the capacity of the $i$ shutter $\left(\mathrm{m}^{3} / \mathrm{h}\right)$.

After we get the indirect electricity consumption values (above), they are added to the related machines' electricity consumption values (below). Then we get the direct values, which contain the indirect (partial) consumption values:

$$
E_{i}=E_{M_{i}}+E_{S_{i}}
$$

where:

- $i$ : machine (or shutter) identification (these are equivalent in this case).

- $E_{i}$ : direct electricity consumption (with indirect value) of $i$ machine.

- $E_{M_{i}}$ : electricity consumption (without indirect value) of $i$ machine.

- $E_{S_{i}}{ }_{i}$ : indirect electricity consumption value of $i$ machine.

With these formulas, our routine is extended in the SCADA system. It was an IT challenge too because this system has its own programming language.

\subsubsection{Calculation with examples}

We provide a sample calculation with given and sample values. A given exhaust fan's constant values related to the shutters:

- Shutter 1 capacity [S1]: $36,550 \mathrm{~m}^{3} / \mathrm{h}$

- Shutter 2 capacity [S2]: $14,500 \mathrm{~m}^{3} / \mathrm{h}$ 
A given exhaust fan electricity consumption:

- In the first 10 minutes [T1]: $18 \mathrm{kWh}$

- In the second 10 minutes [T2]: $17 \mathrm{kWh}$

"Shutter 1 is open" status (we indicate the first 10 minutes with T1 and the second 10 minutes with T2):

- In [T1]: $2 \mathrm{~min}$

- In [T2]: 4 min

Shutter 2 is open status:

- In [T1]: $3 \mathrm{~min}$

- In [T2]: $5 \mathrm{~min}$

Measured electricity consumption by machines:

- In [T1]:

○ $E_{M l}: 25 \mathrm{kWh}$

○ $E_{M 2}: 10 \mathrm{kWh}$

- In [T2]:

○ $E_{M 1}: 30 \mathrm{kWh}$

- $E_{M 2}: 13 \mathrm{kWh}$

Proportionate electricity consumptions of the exhaust fan per shutters and time frames (indirect consumption values): Substituting these values in equation (1), the following results are obtained:

- $E_{S 1, T 1}=11.29 \mathrm{kWh}$ (Within first 10 minutes)

- $E_{S 2, T 1}=6.72 \mathrm{kWh}$ (Within first 10 minutes)

- $E_{S 1, T 2}=11.36 \mathrm{kWh}$ (Within second 10 minutes)

- $E_{S 2, T 2}=5.64 \mathrm{kWh}$ (Within second 10 minutes)

Calculated direct electricity consumptions (machine) and indirect consumption values (exhaust) per time periods: Substituting these values in equation (2), the following results are obtained:

- $E_{M 1+S 1, T 1}=36.29 \mathrm{kWh}$

- $E_{M 2+S 2, T 1}=16.72 \mathrm{kWh}$

- $E_{M 1+S 1, T 2}=41.36 \mathrm{kWh}$

- $E_{M 2+S 2, T 2}=18.64 \mathrm{kWh}$

In this way, we get the direct electricity consumption values, which contain the indirect consumptions of exhaust fans. 


\subsection{Results in Business Intelligence System}

With a BI System, we can join the datasets which come from different sources. The electricity consumption data come from a DBMS. The manufacturing data comes from the ERP system's database. The BI system can handle these different sources easily since the datasets have common fields, with which the joined operation can be executed. These common fields are the following: device identifications and the rounded timestamps. By the electricity consumption data, the device's single daily data entry becomes a 10-minute granularity data. The manufacturing data of a device also becomes a data series with 10-minute with the BI tool; we sum these values and get a total number. Thus, the electricity consumption and the manufacturing data can be combined to a manufacturing machine. In the extended system we assigned the exhaust fans' consumptions to the machines. In this way, we can get not only the total, direct consumptions of the machines, but the useful and useless parts of exhausts' electricity use.

Figure 6 represents the electricity consumption data of machines and the exhaust fans cumulatively. The data was collected during a one-week period in August 2020. In this phase of the implementation, we did not measure all exhaust fans' shutters operation in the factory, this is why there are empty columns related to specific exhausts (and shutters, "Venjakob" machines). The bar chart contains green columns, which represent useful operations, when the machines create products, therefore the working of machine and the exhaust fan is gainful for the company. The red columns represent useless workings, when the machines do not produce any products, therefore the working of machine and the exhaust is not profitable for the company. In this figure, we show only selected machines which are the biggest consumers of electricity. Table 1 shows the related numbers, measured values of Figure 6.

We defined a new KPI in the extended system related to the machines' and exhaust fans' electricity consumption. We named this KPI "Average performance of a machine". The KPI shows how many kWh of electricity were consumed to produce $1 \mathrm{~m}^{2}$ wood material (piece of furniture) by a given manufacturing machine and its connected exhaust fan together. In Figure 7, the data represents one day in August. With this KPI, we can follow the trend of

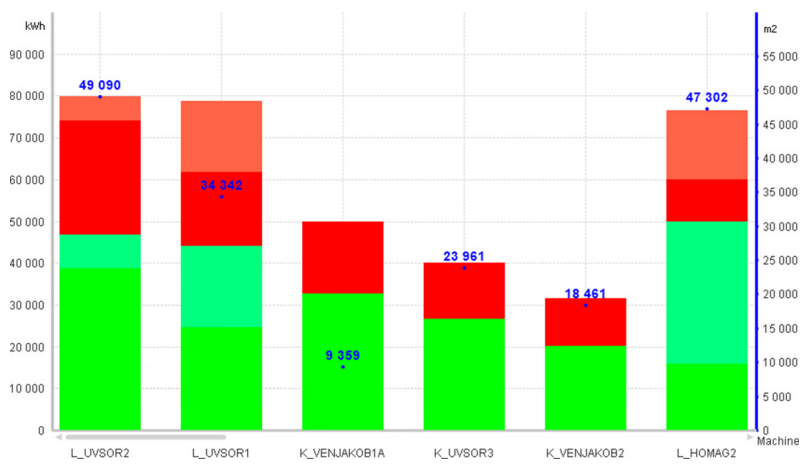

Figure 6: Useful and useless electricity consumptions per every machine (concluding exhaust fans' partial uses). Legends of the chart: 1. light red bars: useless extractor consumption $(\mathrm{kWh}), 2$. red bars: useless machine consumption $(\mathrm{kWh}), 3$. light green bars: useful extractor consumption $(\mathrm{kWh})$, 4. green bars: useful machine consumption $(\mathrm{kWh}), 5$. blue figures: produced volume $\left(\mathrm{m}^{2}\right)$ 
Table 1: The related measured values of Figure 6.

\begin{tabular}{|c|c|c|c|c|c|c|c|}
\hline \multicolumn{2}{|c|}{ Machine's name } & $\begin{array}{l}\text { L } \\
\text { UVSOR } \\
2\end{array}$ & $\begin{array}{l}\text { L } \overline{U V S O R} \\
1\end{array}$ & \multirow{2}{*}{$\begin{array}{l}\mathrm{K} \\
\text { VENJAKOB1 } \\
\mathrm{A} \\
0(0 \%)\end{array}$} & \multirow{2}{*}{$\begin{array}{l}\mathrm{K} \\
\text { UVVSOR3 } \\
0(0 \%)\end{array}$} & \multirow{2}{*}{$\begin{array}{l}\text { K } \\
\text { VENJAKOB2 } \\
0(0 \%)\end{array}$} & \multirow{2}{*}{\begin{tabular}{|l|}
$\mathrm{L}$ \\
HOMAG2 \\
16,556 \\
$(32.8 \%)$ \\
\end{tabular}} \\
\hline $\begin{array}{l}\text { Useless } \\
\text { consumption }\end{array}$ & $\begin{array}{l}\text { Indirect - } \\
\text { extractor }\end{array}$ & $\begin{array}{l}5,781 \\
(41.5 \%)\end{array}$ & $\begin{array}{l}17,053 \\
(46.9 \%)\end{array}$ & & & & \\
\hline$(\mathrm{kWh})$ & $\begin{array}{l}\text { Direct - } \\
\text { machine }\end{array}$ & $\begin{array}{l}27,288 \\
(41.3 \%)\end{array}$ & $\begin{array}{l}17,748 \\
(41.8 \%)\end{array}$ & $\begin{array}{l}17,218 \\
(34.6 \%)\end{array}$ & $\begin{array}{l}13,462 \\
(33.6 \%)\end{array}$ & $\begin{array}{l}11,301 \\
(35.9 \%)\end{array}$ & $\begin{array}{l}10,151 \\
(38.9 \%)\end{array}$ \\
\hline \multirow{2}{*}{$\begin{array}{l}\text { Useful } \\
\text { consumption } \\
(\mathrm{kWh})\end{array}$} & $\begin{array}{l}\text { Indirect - } \\
\text { extractor }\end{array}$ & $\begin{array}{l}8,155 \\
(58.5 \%)\end{array}$ & $\begin{array}{l}19,309 \\
(53.1 \%)\end{array}$ & $0(0 \%)$ & $0(0 \%)$ & $0(0 \%)$ & $\begin{array}{l}33,975 \\
(67.2 \%)\end{array}$ \\
\hline & $\begin{array}{l}\text { Direct - } \\
\text { machine }\end{array}$ & $\begin{array}{l}38,713 \\
(58.3 \%)\end{array}$ & $\begin{array}{l}24,677 \\
(58.2 \%)\end{array}$ & $\begin{array}{l}32,573 \\
(65,4 \%)\end{array}$ & $\begin{array}{l}26,551 \\
(66.4 \%)\end{array}$ & $\begin{array}{l}20,180 \\
(64.1 \%)\end{array}$ & $\begin{array}{l}15,943 \\
(61.1 \%)\end{array}$ \\
\hline \multicolumn{2}{|c|}{ Produced volume $\left(\mathrm{m}^{2}\right)$} & 49,090 & 34,342 & 9,359 & 23,961 & 18,461 & 47,302 \\
\hline
\end{tabular}

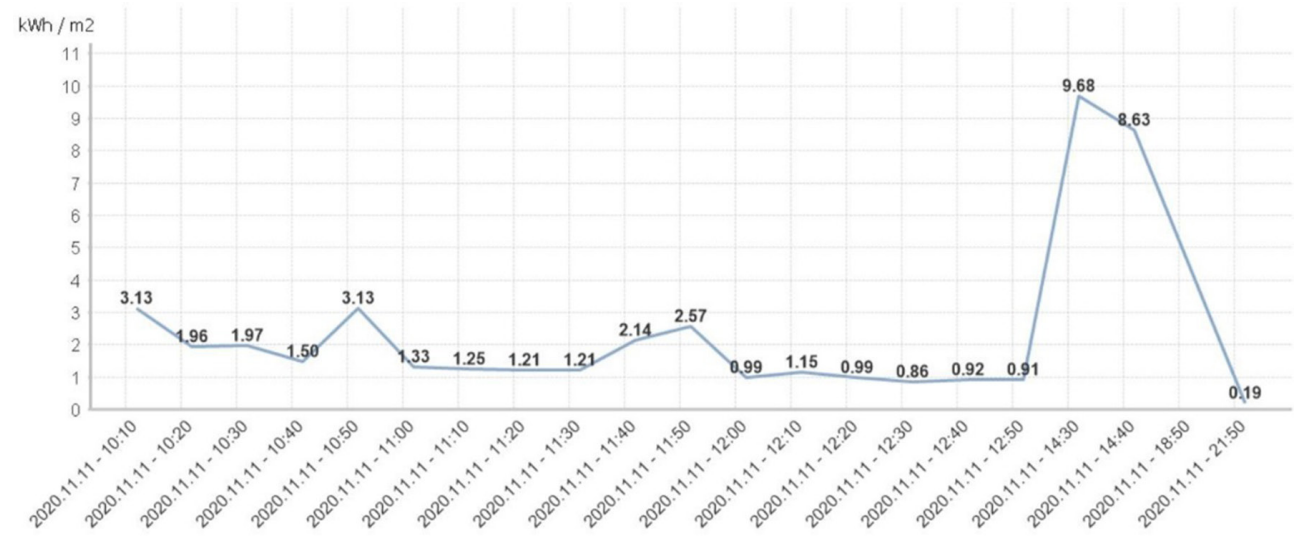

Figure 7: One machine's full (and its related exhaust fan's partial) electricity consumption to produce $1 \mathrm{~m}^{2}$ of a product type in 10 minutes

direct and indirect costs of manufacturing a timber type. The company has thousands of "products" (timber boards); because of their scales, colour codes and wood species combinations, they are assigned unique product identifications. In the future, the management can aim at a target value limit, which they must keep during the manufacturing.

\section{CONCLUSION}

Through the years we have continuously developed a cyber-physical system. In its current form, the system can not only measure the energy consumption and production data of the manufacturing machines, but it is also capable to measure the energy consumption of the other support equipment (for example compressors, exhaust, fans) in terms of utility. In the case of compressors, the energy consumption data can be compared with the performance data, thereby we can assign the amount of compressed air generated by compressors to the energy consumption. Based on this combination, a new efficiency indicator was defined and created into the system.

The SCADA system, which collects the data from sensors, has its own development interface and its own programming language. We defined a scheduled procedure to solve tasks in the company's environment. This procedure consists of the following steps: (1) checking the condition of the shutters every minute (they are open or closed); (2) summing up of the 
opening time of the shutter every 10 minutes. After that, our algorithm calculates the proportionate scale numbers of the shutters' open minutes and the permeabilities. According to this ratio, the energy consumption of the extractors will be added to the energy consumption of the manufacturing machines. This process is required because of the extractors' consumption accounting for about $30 \%$ of the factory's total electricity usage. The extractors generate indirect cost, which is added to the final price of the finished product as a direct cost. These calculations are stored in database and are continuously analysed with the BI system. The results help the company's management to make more effective decisions and to achieve a more optimal manufacturing operation.

\section{ACKNOWLEDGEMENTS}

"Supported by the UNKP-20-3-II new national excellence program of the ministry for innovation and technology from the source of the national research, development and innovation fund."

"Supported by the UNKP-21-4-II new national excellence program of the ministry for innovation and technology from the source of the national research, development and innovation fund."

\section{REFERENCES}

[1] Gludovatz, A. \& Bacsardi, L., Production related IT solutions in the operation of factories, CINTI 2016, 17th IEEE International Symposium on Computational Intelligence and Informatics, Budapest, Hungary, pp. 187-191, Nov. 17-19, 2016.

[2] Garrison, R.H., Noreen, E.W. \& Brewer, P.C., Managerial Accounting, 14th Edition, McGraw-Hill: Irwin, 2011.

[3] Kallam, S., Madda, R.B., Chen, C.-Y., Patan, R. \& Cheelu, D., Low energy aware communication process in IoT using the green computing approach. IET Network, 7, pp. 258-264, 2018. https://doi.org/10.1049/iet-net.2017.0105

[4] Hashmi, S.A., Ali, C.F. \& Zafar, S., Internet of things and cloud computing-based energy management system for demand side management in smart grid. International Journal of Energy Research, 45, pp. 1007-1022, 2021. https://doi.org/10.1002/ er.6141

[5] Li, W. \& Kara, S., Methodology for monitoring manufacturing environment by using wireless sensor networks (WSN) and the Internet of Things (IoT). Procedia CIRP, 61, pp. 323-328, 2017. https://doi.org/10.1016/j.procir.2016.11.182

[6] Avancini, D.B., Rodrigues, J.J.P.C., Rabêlo, R.A.L., Das, A.K., Kozlov, S. \& Solic, P., A new IoT-based smart energy meter for smart grids. International Journal of Energy Research, 45, pp. 189-202, 2021. https://doi.org/10.1002/er.5177

[7] Gludovatz, A. \& Bacsardi, L., The connection of the production and the energy usage in a smart factory. SEFBIS Journal, 12, pp. 60-69, 2018.

[8] Thollander, P. \& Ottosson, M., Energy management practices in Swedish energy-intensive industries. Journal of Cleaner Production, 18, pp. 1125-1133, 2010. https://doi. org/10.1016/j.jclepro.2010.04.011

[9] Koncz, A. \& Gludovatz, A., Efficient energy management system and optimization of resources at a furniture company. SEFBIS Journal, 13, pp. 72-83, 2019. 
[10] Upadhyay, D. \& Sampalli, S., SCADA (Supervisory Control and Data Acquisition) systems: Vulnerability assessment and security recommendations. Computers \& Security, 89, p. 101666, 2020. https://doi.org/10.1016/j.cose.2019.101666

[11] Zhang, S. \& Lang, Z.-Q., SCADA-data-based wind turbine fault detection: A dynamic model sensor method. Control Engineering Practice, 102, p. 104546, 2020. https://doi. org/10.1016/j.conengprac.2020.104546

[12] Guptaa, M. \& Kohli, A., Enterprise resource planning systems and its implications for operations function. Technovation, 26, pp. 687-696, 2006. https://doi.org/10.1016/j. technovation.2004.10.005

[13] AboAbdoa, S., Aldhoiena, A. \& Al-Amrib, H., Implementing enterprise resource planning (ERP) system in a large construction company in KSA. Procedia Computer Science, 164, pp. 463-470, 2019. https://doi.org/10.1016/j.procs.2019.12.207

[14] Bencsik, G. \& Bacsardi, L., Novel methods for analyzing random effects on ANOVA and regression techniques. Knowledge, Information and Creativity Support Systems: Selected Papers from KICSS'2014, Berlin, Germany, pp. 499-509, 2016.

[15] Brichni, M., Dupuy-Chessa, S., Gzara, L., Mandran, N. \& Jeannet, C., BI4BI: A continuous evaluation system for business intelligence systems. Expert Systems with Applications, 76, pp. 97-112, 2017. https://doi.org/10.1016/j.eswa.2017.01.018

[16] Kubinaa, M., Komana, G. \& Kubinova, I., Possibility of improving efficiency within business intelligence systems in companies. Procedia Economics and Finance, 26, pp. 300-305, 2015. https://doi.org/10.1016/s2212-5671(15)00856-4 